\title{
ASPECTOS BIOÉTICOS QUE ENVOLVEM O TRATAMENTO DE PESSOAS QUE VIVEM COM HIV/AIDS
}

\author{
Grazielly Rita Marques Giovelli \\ Gabriel José Chittó Gauer \\ Prisla Ucker Calvetti
}

\author{
Programa de Pós-Graduação em Psicologia \\ Pontifícia Universidade Católica do Rio Grande do Sul (PUCRS) \\ Endereço eletrônico: grazygio@hotmail.com
}

\begin{abstract}
Resumo
O objetivo deste ensaio temático é propor ao leitor uma reflexão acerca das escolhas que a pessoa com HIV/Aids possa ter em relação ao seu tratamento. Descreve as especificidades do tratamento e conceitua a adesão, aspectos bioéticos que envolvem este tema, bem como o papel do profissional da saúde neste cenário. A proposta é suscitar questionamentos sobre como é entendido a adesão no seu mais complexo conceito e se o indivíduo tem direito/possibilidade de escolha em relação ao tratamento. Com isso é fundamental que o profissional da área de saúde entenda como as pessoas desenvolvem habilidades e percepções para lidar com as demandas do ambiente, que afetam sua qualidade de vida ou levam ao adoecimento, para que assim seja possível respeitar o tempo que cada paciente tem para fazer a sua escolha pelo tratamento.
\end{abstract}

Palavras-chave: HIV/Aids, Bioética, adesão ao tratamento, profissional da saúde. 
"Meu médico me passou aquela medicação toda, me senti como se estivesse num mar aberto dentro de uma canoa, sem remo e sem salva vida, agora com o passar do tempo e a maior compreensão do que realmente tenho e para que preciso de um tratamento sinto que estou tomando o comando desta embarcação... tenho minha vida de volta ...em minhas mãos;" Depoimento de C.L., 42 anos, paciente HIV, em tratamento antiretroviral há um ano.

\section{Aspectos biopsicossociais da adesão ao tratamento de HIV/Aids}

O HIV/Aids (vírus da imunodeficiência humana/síndrome da imunodeficiência adquirida) é uma infecção que atingiu o estágio de pandemia no mundo. Desde o seu surgimento, na década de 1980, vem-se observando os fenômenos de heterossexualização, feminização, interiorização e pauperização da epidemia, o que demonstra que a infecção não está mais restrita ao que se considerava como grupos específicos (homossexuais, usuários de drogas injetáveis e profissionais do sexo, por exemplo), atingindo a população de forma geral.

A realidade das pessoas vivendo com HIV/Aids vem passando por mudanças nos últimos anos, em grande parte por causa dos avanços relacionados ao surgimento da terapia antiretroviral (TARV), que resultou em aumento da sobrevida, diminuição das internações por doenças oportunistas , queda da mortalidade (MARINS et al., 2003) e qualidade de vida (SEIDL, 2005; CASTRO; REMOR, 2004).

Com o advento da TARV, conhecida também como HAART- Highly Active Antiretroviral Therapy, a Aids assumiu características de doença crônica, em especial nos países onde o acesso aos medicamentos é efetivamente garantido (BAER; ROBERTS, 2002; BRASIL, 2007/2008; WU, 2000). Diante da tendência à cronicidade, surgem outros desafios, determinando a necessidade de novas práticas relacionadas ao tratamento no cotidiano das pessoas vivendo com HIV/Aids (PVHA).

A finalidade da TARV está em reduzir a morbimortalidade e melhorar a qualidade de vida das pessoas, por meio da supressão viral, o que permite retardar ou evitar o surgimento da imunodeficiência (BRASIL, 2007). Para Bastos (2006), os resultados obtidos com o tratamento - a redução progressiva da carga viral e a manutenção e/ou restauração do funcionamento 
do sistema imunológico - têm sido associados a benefícios marcantes na saúde física das pessoas soropositivas e permitido que elas retomem e concretizem seus projetos de vida. Estudos têm mostrado que a eficácia do tratamento, expressa nos níveis de supressão viral, exige que o uso do esquema terapêutico deva ser igual ou superior a $95 \%$ das doses prescritas. A adesão insatisfatória pode estar associada ao desenvolvimento de resistência viral (SMITH, 2000; BRASIL, 2007).

Cabe ressaltar que com a introdução da terapia antiretroviral tem sido observada uma importante diminuição das internações hospitalares, devido a complicações oportunistas e da mortalidade associada ao HIV em diversos países. O diagnóstico de infecção pelo HIV, atualmente pode ser considerado uma doença crônica apresentando implicações médicas, psicológicas e sociais significativas, impondo esforços adaptativos relevantes às pessoas soropositivas. Embora seja potencialmente controlável ela traz consigo novos desafios para os pacientes e profissionais de saúde que trabalham nessa área.

No entanto, em virtude da adesão ao tratamento assumir uma importância crucial frente à perspectiva de uma vida longa e com qualidade, estudiosos buscam entender a dinâmica desta entre as pessoas que vivem com HIV/Aids.

Diante disso ressaltamos que uma definição mais ampla e abrangente assinala que adesão (BRASIL, 2007, 2008):

- É um processo dinâmico e multifatorial que inclui aspectos físicos, psicológicos, sociais, culturais e comportamentais, que requer decisões compartilhadas e corresponsabilizadas entre a pessoa que vive com HIV, a equipe e a rede social.

- Deve ser entendida como um processo de negociação entre o usuário e os profissionais de saúde, no qual são reconhecidas as responsabilidades específicas de cada um, que visa a fortalecer a autonomia para o autocuidado.

- Transcende à simples ingestão de medicamentos, incluindo o fortalecimento da pessoa vivendo com HIV/Aids, o estabelecimento de vínculo com a equipe de saúde, o acesso à informação, o acompanhamento clínico-laboratorial, a adequação aos hábitos e necessidades individuais e o compartilhamento das decisões relacionadas à própria saúde, inclusive para pessoas que não fazem uso de TARV.

Já para Tuldrá e Wu (2002) de alguma forma a conduta de adesão pode ser considerada similar à aquisição de um hábito: 

suporte social, a vivência plena da sexualidade, a adesão ao tratamento e a concretização dos projetos de vida são alguns dos tópicos de interesse diante da perspectiva de uma vida longa e com qualidade das pessoas soropositivas (SEILD, 2005; WU, 2000).

Portanto, ainda que tenha decorrido mais de vinte anos desde sua descoberta, existem algumas lacunas na assistência aos portadores do HIV/Aids, principalmente no que concerne à convivência da pessoa com a doença, na busca de atender as suas necessidades psicossociais e incentivar a capacidade de autonomia para cuidar de si mesma.

Desta forma, se a preocupação no início da epidemia era a iminência de finitude com a morte logo após o diagnóstico, atualmente, soma-se à ingestão concomitante de diversos medicamentos sob rigorosas condições de administração e por tempo indeterminado ao medo da morte, a necessidade de reestruturação da vida, a fim de conviver com a presença do vírus no organismo.

O tratamento veio para prolongar a vida dos portadores e lhe proporcionar maior qualidade de vida, contudo questionamos que qualidade é esta? Será que não seria o prolongamento da vida? $\mathrm{O}$ paciente em questão sabe realmente quais são as ameaças de não tomar o medicamento? Tem a informação sobre quais são os seus riscos e o que representa tomar a medicação? Conseguiu entender adequadamente as informações dadas pela equipe de saúde?

Uma série de fatores afeta o perfil de morbimortalidade da doença, como o acesso às informações, aos meios de prevenção das infecções oportunistas, aos exames laboratoriais, aos antiretrovirais, à qualidade da assistência prestada, à adesão ao tratamento, ao diagnóstico precoce das infecções e às medidas terapêuticas cabíveis. Artigos científicos defendem que a nãoadesão aos novos medicamentos para a Aids (antiretrovirais) é considerada como um dos mais ameaçadores perigos para a efetividade do tratamento, no plano individual e coletivo.

Com base nisso observando que existem muitos fatores que estão relacionados ao tratamento que podem ser considerados fatores colaborativos para a diminuição da adesão ao tratamento, daremos destaque alguns destes fatores a partir de estudos realizados (KELLY; KALICHMAN, 2002; SeEIDL et al. 2007) sobre este tema: 
- Número de doses e de combinações: embora o número de doses tenha diminuído, ainda existem combinações terapêuticas compostas por números de doses significativas. E além das composições, alguns medicamentos precisam ser ingeridos com alimentos, outros em jejum ou em sequências temporais combinadas com outros medicamentos, o que exige organização e compromisso do paciente em relação ao seu tratamento.

- Efeitos colaterais: são os mais variados como: diarréia, alucinações, dores de cabeça, entre outros. Portanto, daremos destaque para a síndrome lipodistrófica que é definida como uma síndrome que acomete pessoas soropositivas e tem como principal característica a má distribuição da gordura corporal. A lipodistrofia pode ter associação das alterações no metabolismo glicêmico, resistência insulínica e dislipidemia. Já as alterações corpóreas têm sido relacionadas à lipohipertrofia (aparecimento de gordura dorsocervical, expansão da circunferência do pescoço, aumento do volume dos seios e acúmulo de gordura na região abdominal) e à lipoatrofia (diminuição de gordura periférica, com perda de tecido subcutâneo na face, braços, pernas e nádegas). Para Seidl e Machado (2008), mesmo dieta alimentar e exercícios físicos regulares não constituírem uma solução definitiva para os efeitos da lipodistrofia. Estudos apontam que mudanças nos hábitos alimentares e a prática de atividade física são importantes para que alguns resultados positivos sejam alcançados.

- Mudanças no estilo de vida: adequar horários de medicamentos à convivência pessoal, profissional e social.

- Tempo de tratamento: quando o paciente não adere na fase inicial ou faz tentativas frustradas de adesão observa-se que o tempo de tratamento aumenta e com isso pode levar a frustração e falta de motivação, comprometendo assim a continuidade do mesmo.

- Relação com os profissionais de saúde: o relacionamento de boa qualidade entre paciente e o profissional da saúde é fundamental, como a transparência na comunicação, a disposição dos profissionais em envolver os pacientes em decisões referentes ao tratamento e a intensidade dos efeitos colaterais.

- Acesso ao serviço: muitas vezes a distância entre o local que o paciente vive e onde faz seu atendimento pode gerar dificuldade para o cumprimento de protocolos terapêuticos, ou a dificuldade financeira em não possuir condições de custear meio de transporte e consequentemente não ter condições para ir até o posto de saúde. 
- Conveniência para agendar o retorno e os procedimentos: em se tratando de serviço público algumas pessoas têm dificuldade em agendar as consultas e os procedimentos bem como o retorno destes.

Diante do acima exposto observa-se que os efeitos do diagnóstico e do tratamento atingem uma gama de fatores da vida das pessoas com HIV/Aids. Além do físico, do psicológico e do social, ela precisa lidar diariamente com o preconceito que ainda, infelizmente, existe entre nós. Com isso discutir adesão e sensibilizar o paciente a fazer o tratamento de forma plena é muito importante, contudo considerar que é um tratamento complexo e muitas vezes passível de ser interrompido pelos diversos fatores que já citamos é imprescindível.

\section{Aspectos bioéticos da adesão ao tratamento de pessoas que vivem com HIV/Aids}

Buscamos na psicologia da saúde a compreensão deste fenômeno. Este campo vê na Bioética uma área de atuação e reflexão, não só no que diz respeito à interface com o prognóstico da doença, a importância das pesquisas psicossociológicas como também o bem-estar biopsicossocial do ser humano.

Para melhor arguir os pontos discutidos neste texto, dentre os princípios da Bioética destacamos neste momento a Autonomia; princípio que se refere à capacidade de uma pessoa decidir fazer ou buscar aquilo que julga ser o melhor para si. É importante salientar que uma das bases teóricas utilizadas para o princípio da Autonomia é o pensamento de John Stuart Mill (1909), o qual propôs "sobre si mesmo, sobre seu corpo e sua mente, o indivíduo é soberano", corroborando temos Benjamim Cardozo, em 1914, afirmando que todo ser humano de idade adulta e com plena consciência, tem o direito de decidir o que pode ser feito no seu próprio corpo.

Para Beauchamp e Childress (1994), a autonomia tem diferentes significados, tão diversos como autodeterminação, direito de liberdade, privacidade, escolha individual, livre vontade, comportamento gerado pelo próprio indivíduo e ser propriamente uma pessoa.

Para encorpar ainda mais a proposta de discussão evidenciamos o "Relatório Belmont Princípios e Diretrizes Éticas Para a Proteção de Pacientes Humanos em Pesquisas” (1978), o qual estabeleceu as bases para a adequação ética da pesquisa nos 
Estados Unidos e é considerado até o presente momento uma referência no que se refere à ética. Ou seja, o relatório denominava este princípio como Princípio do Respeito às Pessoas. Nesta perspectiva propunha que a autonomia incorpora, pelo menos, duas convicções éticas: 1) que os indivíduos devem ser tratados como agentes autônomos, e 2) que as pessoas com autonomia diminuída devem ser protegidas.

Para Goldim (2001), uma pessoa autônoma é um indivíduo capaz de deliberar sobre seus objetivos pessoais e de agir na direção desta deliberação, com isso respeitar a autonomia é valorizar a consideração sobre as opiniões e escolhas, evitando, da mesma forma, a obstrução de suas ações, a menos que elas sejam claramente prejudiciais para outras pessoas. Para tanto, não apresentar este respeito é não considerar os julgamentos da pessoa autônoma, é recusar ao indivíduo a liberdade de agir com base em suas percepções ou omitir informações necessárias para que possa ser feito um julgamento, quando não há razões convincentes para fazer isto.

Sendo assim, um ponto a ser ressaltado é que o paciente ao ser informado sobre seu diagnóstico, sobre o seu tratamento e suas repercussões tem o direito de fazer sua opção e esta deveria ser respeitada. Pois o homem é único ser em quem a vida se torna capaz de "reflexão" sobre si, de autodeterminação; é o único ser vivo que tem a capacidade de captar e descobrir o sentido das coisas, e dar sentido às expressões e à sua linguagem consciente (SGRECCIA, 1996).

Um dos caminhos que acreditamos é algo que se estuda na maioria dos cursos de áreas da saúde, mas que não é possível aprender pela via exclusivamente intelectual, e sim vivenciar, é a empatia. Ou seja, conseguir colocar-se no lugar do outro sem que se saia completamente do seu lugar; uma tentativa de sentir o que outro sente, caso estivéssemos em sua situação. Desta posição, torna-se mais plausível compreender sua necessidade de saber o que vai mudar em sua vida, no seu corpo e nas suas relações.

Em se tratando de pacientes acometidos de doenças crônicas a dificuldade para seguir o tratamento prescrito é muito grande, no caso dos antiretrovirais, não seria diferente devido à apreensão constante aos efeitos secundários e aos fracassos terapêuticos. Todavia destacamos a soropositividade para o HIV como sendo uma experiência extremamente significativa na vida do indivíduo, mesmo que potencialmente adversa, gera em alguns casos a mudança dos hábitos e da rotina de vida. Cuidados com a saúde 
(física, mental e espiritual) passam a fazer parte da rotina de pessoas que, antes do diagnóstico de HIV/Aids, não tinham esse tipo de preocupação.

Os modos de enfrentamento diante de uma situação nova - viver com uma enfermidade crônica - modificam-se, dependendo de fatores pessoais (características de personalidade, conhecimentos e crenças sobre a enfermidade e o tratamento, entre outros) e socioambientais (disponibilidade de apoio social, acesso a serviços de saúde e a recursos da comunidade, etc.) (BRASIL, 2007). Contudo, cada pessoa tem o seu tempo para assimilar o resultado positivo para HIV/Aids e assumir uma postura mais proativa diante de sua infecção. Diante desta situação é possível que o indivíduo negue o próprio resultado, que duvide da legitimidade do teste diagnóstico ou que tenha dificuldade de tomar para si a responsabilidade da infecção. Esse comportamento de negação pode ser uma forma de fugir da realidade, como uma maneira de se adaptar a sua nova condição.

No entanto, no contexto do HIV/Aids, as diferenças particulares podem servir para justificar a variedade de reações possíveis diante da decisão em aderir ou não ao tratamento. Indicando assim, que indivíduos soropositivos para HIV podem superar a adversidade trazida pela infecção com uma boa qualidade de vida, e esse bom desempenho num contexto extremamente difícil pode ser, então, característico de pessoas resilientes, desde que eles possam fazer essa escolha por si (CARVALHO et al., 2007).

Embora acreditemos também na efetividade do tratamento e na diversidade de atitudes frente ao tratamento, questionamos qual a relação que está sendo estabelecida entre paciente, o medicamento e a adesão do mesmo para com tratamento bem como com sua vida? O nosso desejo é inquietar neste diálogo de qual a abordagem para com esse paciente, será que antes de tratarmos através da prescrição não deveríamos explorar qual a atitude dessa pessoa frente à sua vida e, consequentemente, ao seu tratamento? Porque devemos lembrar que, antes do tratamento, temos um diagnóstico o qual é tão ou mais difícil do que iniciar o tratamento em si, pois com ele vem o questionamento, a revolta, o medo, o preconceito e a discriminação. E antes ainda do diagnóstico temos um ser humano que em algum momento se infectou com um vírus, que provavelmente, ao ter tido conhecimento de sua condição sorológica, passou por algumas mudanças em sua vida, em seu modo de ver as coisas, o mundo e as pessoas. 
Portanto, não basta enquanto profissional da área da saúde apresentar apenas os benefícios e tratar o paciente como se esse não tivesse escolha. A escolha sempre deveria ser do paciente e o nosso papel é apresentar e até mesmo sensibilizar esse paciente, mas não impor a adesão, respeitando sempre o seu tempo. Em nenhum momento estamos questionando a eficácia e a necessidade da realização do tratamento e sim de como este é estabelecido.

Muitas vezes a prescrição do tratamento é indicada com o intuito de promover qualidade de vida ao paciente, então perguntamos que qualidade de vida é essa, já que ressaltamos anteriormente algumas das dificuldades do tratamento? Com tantos efeitos colaterais, estigmas, discriminação e falta de outra opção? Não seria o prolongamento da vida? Já que esse paciente muitas vezes não tem outra opção, senão de tomar a medicação, sem mesmo saber ou compreender para que a mesma serve e quais as dificuldades que ele vai passar para ter essa tão esperada qualidade de vida.

$\mathrm{O}$ paciente pode e deve saber as especificidades do seu tratamento, mas muitas vezes por achar que o profissional da saúde é o único detentor da verdade, acerca de sua saúde (e ele realmente tem conhecimento e técnica para estar na posição de profissional e propor bem-estar ao paciente) ele não questiona, simplesmente acata, sem mesmo ter coragem de perguntar se o que está sentindo é esperado ou não na sua condição.

Não queremos generalizar, pois temos muitos profissionais da saúde e pacientes, cada qual com suas peculiaridades, contudo, refletimos neste momento sobre os direitos dos pacientes, porque o dever já conhecemos, que é o de tomar o medicamento, porque senão morre. Morrer ele vai morrer, aliás, todos vamos, apenas não podemos "matá-lo" antes da hora, por isso ele pode e deve ser ativo nessa relação. Queremos deixar explícito que não estamos incentivando o paciente a não tomar o medicamento e sim incentivando que cada paciente compreenda ainda melhor o que significa o tratamento e adesão e encare este como SUA escolha de vida, com propriedade de causa e, caso sua escolha for outra, que a mesma seja respeitada.

\section{Considerações finais}

A adesão é um processo dinâmico e multifatorial que inclui aspectos físicos, psicológicos, sociais, culturais e comportamentais, que requer decisões compartilhadas e co-responsabilizadas entre 
a pessoa que vive com HIV, a equipe e a rede social (BRASIL, 2007). Deve ser entendida como um processo de negociação entre o usuário e os profissionais de saúde, no qual são reconhecidas as responsabilidades específicas de cada um, que visa a fortalecer a autonomia para o autocuidado.

Sendo assim é fundamental que os profissionais de saúde reconheçam que a adesão é um fenômeno que deve ser trabalhado junto ao paciente de forma sistematizada, com desenvolvimento de ações que favoreçam uma atuação efetiva dos profissionais e uma incorporação do tratamento pelo paciente (COLOMBRINI; LOPES: FIGUEIREDO, 2006). Para tanto, a equipe de saúde deve conhecer os fatores que possam intervir na adesão, sendo imprescindível o reconhecimento das particularidades de seu paciente em especial.

Por fim, cabe aos profissionais e equipe de saúde se valerem da compreensão dos fatores que dificultam e que facilitam a adesão, mediante a descrição por parte do próprio paciente de suas experiências, atitudes e crenças sobre a enfermidade e o tratamento, para ajudá-lo a compreender a importância da TARV e melhorar o comportamento de adesão (RUSSEL et al., 2003). Nesse sentido é fundamental que o profissional da área de saúde entenda como as pessoas desenvolvem habilidades e percepções para lidar com as demandas do ambiente, que afetam sua qualidade de vida ou levam ao adoecimento.

No entanto, pelo fato do ser humano sempre ser objeto de questionamentos e investigações, propomos com o presente texto um "aperitivo" para abrir novos leques deste tema tão importante e difícil de ser concretizado: respeitar escolhas. Cada pessoa deve encontrar no seu tempo o sentido para sua vida. Quando se consegue entender o valor que a vida representa, a escolha de tomar o medicamento, fazer o tratamento, se relacionar com as pessoas, viver socialmente são consequências de uma escolha ainda maior que é viver.

\section{Referências}

BAER, Markus; ROBERTS, Jillian. Complex HIV treatment regimens and patient quality of life. Canadian Psychology, 43 (2), p.115-121, 2002.

BRASIL. Ministério da Saúde. Secretaria de Vigilância em Saúde. Programa Nacional de DST e Aids. Diretrizes para o fortalecimento 
das ações de adesão ao tratamento para pessoas que vivem com HIV/

Aids. Brasília: MS, 2007.

BRASIL. Ministério da Saúde. Secretaria de Vigilância em Saúde. Programa Nacional de DST e Aids. Manual de adesão ao tratamento para pessoas vivendo com HIV e Aids. Brasília: MS, 2008.

BASTOS, Francisco Inácio. Aids na terceira década. Rio de Janeiro: Edit. Fiocruz, 2006.

BEAUCHAMP, Tom; CHILDRESS, James The principles of biomedical ethics. 4. ed. New York: Oxford, 1994.

CASTRO, Elisa Kern; REMOR, Eduardo Augusto. Aspectos Psicossociais e HIV/Ads: um estudo bibliométrico (1992-2002): comparativo dos artigos publicados entre Brasil e Espanha. Psicologia: Reflexão e Crítica, 17(2), p. 243-250, 2004.

CARDOZO, Benjamin. 1914. Dissenting opinion in Schloendorff v. Society of New York Hospital. 211 N.Y. 125, 105 N.E. 92.

CARVALHO, Fernanda Torres; MORAIS, Normanda Araujo; KOLLER, Silvia Helena; PICCININI, Cesar Augusto. Fatores de proteção relacionados à promoção de resiliência em pessoas que vivem com HIV/Aids. Caderno de Saúde Pública, 23 (9), 2007.

COLOMBRINI, Maria Rosa Ceccato; LOPES, Maria Helena Baena de Moraes; FIGUEIREDO, Rosely Morales. Adesão à terapia antiretroviral para HIV/Aids. Revista da Escola de Enfermagem da USP, 40 (4), 2006.

FIGUEIREDO, Rosely Morales; SINKOC, Veronica Maria; TOMAZIM, Cybele Cristina; GALLANI, Maria Cecilia Bueno Jayme; COLOMBRINI, Maria Rosa Ceccato. Adesão de pacientes com Aids ao tratamento com Antirretrovirais: dificuldades relatadas e Proposição de medidas atenuantes em um Hospital Escola. Revista Latino-Americana de Enfermagem, 9(4), 2001.

GOLDIM, José Roberto (2001). Conceitos fundamentais da moral à Bioetica. Acesso em: 20 jan. 2010. Disponível em: http://www.bioetica. ufrgs.br.

KELLY, Jeffrey; KALICHMAN, Seth. Behavioral research in HIV/ Aids primary and secondary prevention: Recent advances and future directions. Journal of Consulting and Clinical Psychology, 70, 626639, 2002. 
MARINS, José Ricardo; JAMAL, Leda; CHEN, Sanny; BARROS, Marilisa; HUDES, Esther; BARBOSA, Aristides; CHEQUER, Pedro; TEIXEIRA, Paulo; HEARST, Normane. Dramatic improvement in survival among adult Brazilian AIDS patients. AIDS, 17, p. 1675-1682, 2003.

MILL, John Stuart. On liberty. Boston: Collier, 5, 1909.

SGRECCIA, Elio. Manual de Bioética. São Paulo: Loyola, 1996..

SEIDL, Eliane Maria Fleury. Enfrentamento, aspectos clínicos e sociodemográficos de pessoas vivendo com HIV/AIDS. Psicologia em Estudo, 10(3).

SEIDL, Eliane Maria Fleury; MELCHÍADES, Adriana; FARIAS, Viviane; BRITO, Alexander. Pessoas vivendo com HIV/Aids: variáveis associadas à adesão ao tratamento anti-retroviral. Cadernos de Saúde Pública, 23 (10), p. 2305-2316, 2007.

SEIDL, Eliane Maria Fleury; MACHADO, Ana Claudia Almeida. Bem-estar psicológico, enfrentamento e lipodistrofia em pessoas vivendo com HIV/Aids. Psicologia em Estudo, 13 (2), 2008.

RUSSEL, Cynthia K.; BUNTING, Sheila M.; GRANEY, Marshall; HARTIG, Margareth T.; KISNER, Patricia; BROWN, Brian. Factors that influence the medication decision making of persons with HIV/ Aids: a taxonomic exploration. Journal of the Association of Nurses in AIDS Care, 14 (4) p. 46-60, 2003.

SMITH, Richard. Adherence to antiretroviral HIV drugs: how many doses can you miss before resistance emerges? Proceedings Royal Society B., 273, p. 617-24, 2000.

TULDRÁ, Albert; WU, Albert. Interventions to improve adherence to antiretroviral therapy. Journal of Acquired Immune Deficiency Syndromes, p.154-157, Suppl 3, 2002.

WU, Albert. Quality of life assessment comes of age in the era of highly active antiretroviral therapy. AIDS, 14, 1449-1451, 2000. 


\section{Abstract}

This paper aimed theme is to propose to the reader to reflect about the choices that people with HIV / AIDS may have regarding their treatment. It describes the specificities of such treatment and appraises membership, bioethical issues surrounding this topic as well as the role of health care in this scenario. The proposal is to raise questions about how the adherence is understood as a more complex concept and if the individual has the right / choice regarding treatment. Thus, it is essential that the healthcare professional understands how people develop skills and insights to cope with the demands of the environment which affect their quality of life or lead to illness so that one can respect the time that each patient has to make a choice for treatment.

Keywords: AIDS, Bioethics, adherence to treatment, health professional. 
